\section{Вновь о «борьбе» с урожаем, или куда идет локомотив российской экономики ${ }^{1}$}

А.К. ТУЛохонов, академик РАН, научный руководитель Байкальского института природопользования СО РАН, Улан-Удэ.

E-mail: aktulohonov@binm.ru

В статье определены основные аспекты развития сельского хозяйства России. Проведен анализ эффективности государственной поддержки сельского хозяйства. Обоснован вывод о том, что в условиях рыночной экономики сельскохозяйственная наука не может существовать без государственной поддержки. Подчеркивается, что главным условием стабильности государственного устройства России в новых геополитических и экономических реалиях остается сохранение потенциала сельского населения.

Ключевые слова: экономика сельского хозяйства, продовольственная безопасность, сельскохозяйственная наука, государственная поддержка сельского хозяйства

После принятия известного федерального закона «О Российской академии наук, реорганизации государственных академий наук и внесении изменений в отдельные законодательные акты Российской Федерации» в сферу ответственности Академии наук вошли проблемы обеспечения продовольственной безопасности страны, решение текущих и перспективных задач развития аграрного комплекса и социальных проблем села, которые в рыночных условиях чаще всего имеют разнонаправленные векторы интересов.

\section{Успехи аграрной отрасли и проблемы социального развития}

Впервые за многие годы действующие и бывшие руководители отрасли, а также ведущие экономисты приводят многочисленные цифры, демонстрирующие современные достижения сельского хозяйства. По данным академика А.Г. Аганбегяна [Аганбегян, 2017], на фоне общей стагнации экономики за 10 лет продукция агрокомплекса выросла на $35 \%$, прирост ВВП за счет сельского хозяйства в стране составил 4-5\%, что обеспечило

Работа выполнена в рамках государственного задания Байкальского институт природопользования СО РАН, проект № 0339-2016-0002. наполовину наш экономический рост. Феноменальные успехи аграрной отрасли позволили ей стать локомотивом социальноэкономического роста России. Вслед за наукой бывший министр сельского хозяйства Е. Скрынник [Скрынник, 2017] докладывает об успехах некогда возглавляемой ею отрасли. За 2000-2015 гг. производство овощей и пшеницы выросло вдвое, рапса, сои и кукурузы - почти в восемь раз 2 , в конечном итоге к 2016 г. рентабельность сельского хозяйства достигла $22 \%$, а доля прибыльных сельхозпредприятий $-85 \%{ }^{3}$.

Но статистика - как известно, вещь лукавая. Она же утверждает, что вместе с ростом производства продукции сельского хозяйства три года подряд сокращаются реальные доходы населения: в 2014 г. они снизились на $0,7 \%$, в 2015 г. - 3,2\%, в 2016 г. $5,8 \%{ }^{4}$. Эти цифры в сочетании с увеличением доли населения с доходами ниже прожиточного минимума ${ }^{5}$ и разрушенными колхозными фермами, брошенными деревнями, обилием импортного продовольствия в наших магазинах неизбежно порождают сомнения в конечной результативности аграрных достижений. Более того, возникает естественный вопрос: а тем ли курсом идет новый локомотив российской экономики?

На первый взгляд, небывалый урожай зерновых 2017 г. на российских полях (более 130 млн т) вселяет большие надежды на решение проблемы продовольственной безопасности страны. За счет экспорта зерновых планируется получить до 20 млрд долл., что значительно больше, чем от продажи российского вооружения. По законам рыночной экономики, рекордный урожай зерновых должен привести к снижению цен, что может способствовать росту производства мяса и молока.

Однако понемногу стихли победные реляции Минсельхоза. Та же статистика утверждает, что минимальная корзина продуктов питания к концу 2017 г. по сравнению с 2016 г. подорожала на $1,28 \% \%^{6}$

\footnotetext{
2 Российский стат. ежегодник. 2017: Стат.сб./Росстат. М., 2017. С. 368.

Основные показатели сельского хозяйства в России в 2016 г. М., 2017. С. 33

${ }^{4}$ Российский стат. ежегодник. 2017. С. 144.

Там же. С. 140

6 Стоимость условного (минимального) набора продуктов питания. Единая межведомственная информ.-стат. система [Эл. ресурc]. URL: https://www.fedstat. ru/indicator/31481(дата обращения: 12.02.2018).
} 
За четверть века демократических реформ потребление молока в стране сократилось с 387 кг на душу населения в 1990 г. $^{7}$ до 236 кг в 2016 г., что на 89 кг меньше, чем предполагают рекомендованные в 2016 г. нормы потребления пищевых продуктов, отвечающие современным требованиям здорового питания9. Такой дефицит вынуждает увеличивать импорт молочной продукции, достигший в 2016 г. 6950 тыс. т. При этом, как ни странно, на фоне роста внутренних цен на молочную продукцию увеличивается и ее экспорт, который в 2016 г. составил 645 тыс. т, что превышает экспорт мяса $\left(228\right.$ тыс. т) ${ }^{10}$.

И причина здесь не только в аппетитах посредников и надбавках сетевых магазинов или в коррупции чиновников. Необходимо признать, что в очередной раз, по давней российской традиции, лозунги «борьбы за урожай» сменились очередной кампанией «борьбы с урожаем».

Первый вопрос сегодня для сельчан: «Куда девать собранный с таким трудом хлеб?». Еще с советских времен на селе нет достаточного объема зернохранилищ, сушилок и элеваторов, а имеющиеся мощности забиты госрезервом и прошлогодним урожаем. По всем прогнозам, к будущему полевому сезону треть рекордных достижений может быть списана и не попадет даже в кормушки буренок.

Отсюда возникает другой вопрос: «Как реализовать результаты своего труда?». К примеру, в Новосибирской области валовый сбор зерна в 2017 г. - 3 млн т, что почти на 20\% превышает показатели 2016 г. ${ }^{11}$ При этом закупочные цены упали по сравнению с прошлым годом с 11 тыс. руб./т до 4 тыс. руб., что значительно ниже себестоимости. При отсутствии емкостей для хранения

Народное хозяйство СССР в 1990 году. Стат. ежегодник. М., 1991 [Эл. ресурс] URL: http://istmat.info/node/433 (дата обращения: 08.02.2018).

Потребление основных продуктов питания населением Российской Федерации Федеральная служба гос. статистики [Эл. pесурc]. URL: http://www.gks.ru/wps/wcm/ connect/rosstat_main/rosstat/ru/statistics/publications/catalog/doc_1286360627828 (дата обращения: 08.02.2018).

Приказ Министерства здравоохранения РФ «Об утверждении рекомендаций по рациональным нормам потребления пишевых продуктов, отвечающих современным требованиям здорового питания» № 614 от 19.08.2016 г.

${ }^{10}$ Основные показатели сельского хозяйства в России в 2016 г. С. 21

11 Уборка зерновых. Отчетность на 16 ноября 2017 г. Министерство сельского хозяйства Новосибирской области. Оперативный анализ по НСО [Эл. ресурс] URL: file:///C:/Users/OEM/Downloads/04._rastenievodstvo_uborka_zernovyh.pdf (дата обращения: 12.02.2018). и перерабатывающих производств спросом пользуется только зерно высших категорий. И так практически по всем крупнейшим российским аграрным регионам.

В этих условиях многие товаропроизводители стремятся продать свой урожай за границу. Однако и здесь проблемы: железная дорога и морской транспорт не в состоянии обеспечить возрастающие объемы экспортных поставок. Не хватает вагонов, портовые сооружения, традиционно предназначенные для минерального сырья, не могут переработать «свалившийся» на них урожай, а цены за эти перевозки могут осилить только крупные агрохолдинги. Правительство вновь вынуждено выделять субсидии товаропроизводителям на покрытие железнодорожных тарифов.

Следует отметить, что рост объема экспорта происходит при падении цен практически по всем основным группам продовольствия. Только за 2012-2015 гг. цены на пшеницу упали на 27\%, ячмень $-26 \%$, масло подсолнечное - $14 \%$, муку - на $35 \%$. Одной из причин является внутренняя конкуренция российских производителей, демпингующих свои товары на внешнем рынке. При отсутствии государственного регулятора за последние два года число отечественных компаний - экспортеров зерна выросло примерно с полутысячи до более восьми сотен [Жога, 2017].

Подобная политика наблюдается и в российских нефтегазовых компаниях: государство в стремлении повысить поступления в бюджет и переработку сырья на внутреннем рынке вводит дополнительные налоги на вывоз сырой нефти и газа. Другая ситуация в аграрном секторе экономики в целом, в котором для поощрения экспорта сняты таможенные пошлины на зерно до 1 июля 2018 г.

Как результат, несмотря на все призывы руководства страны к переходу на высокотехнологичные производства, сырьевая «игла» нефтяной экономики России в последние годы дополняется увеличением экспортных поставок продукции сельского хозяйства. И основная прибыль опять же достается зарубежным производителям: там из нашего урожая получают продукцию с большой добавленной стоимостью, которая возвращается в российские магазины в виде хамона, моцареллы, пасты и других деликатесов. 
При такой экспортной политике, а точнее, ее отсутствии, вряд ли можно надеяться, что прогнозируемая выручка от продажи отечественных сельхозпродуктов дойдет до государственной казны в ожидаемом объеме.

\section{Проблемы локомотива российской экономики}

Для руководителей, не очень знакомых с историей, следует напомнить, что во времена С.Ю. Витте и П.А. Столыпина с целью поощрения развития собственного кормопроизводства и животноводства в России существовала особая наценка при вывозе зерна. В конечном итоге продажа масла на внешнем рынке, целиком основанная на росте сибирского маслоделия, дала казне золота вдвое больше, чем вся сибирская золотопромышленность [Столыпин, Кривошеин, 1911].

А сейчас при рекордных достижениях крупного агробизнеса мелкие и средние фермеры вынуждены отдавать свой урожай любым перекупщикам, которые предлагают цены значительно ниже себестоимости. Естественно возникает новый вопрос: «А кому нужны такие объемы урожаев, если его невозможно достойно реализовать на внутреннем рынке, переработать, вывезти за границу или сохранить до лучших времен?».

И это только тонкий слой видимых проблем «борьбы с российским урожаем». Пресса и руководство, имеющее отношение к сельскому хозяйству, в лучших советских традициях докладывают, что село перестало быть «черной дырой», и бюджетные деньги, вложенные в аграрный комплекс, возвращаются сегодня сторицей.

И действительно, по данным той же Е. Скрынник [Скрынник, 2017], сельскому хозяйству оказана беспрецедентная поддержка, которая за последние десять лет превысила сумму 3,5 трлн руб.: в 2000 г. она составляла 9,4 млрд руб., в 2017 г. - 242 млрд руб., что на 19 млрд руб. больше, чем в 2016 г. Ни одна отрасль российской экономики не получала ежегодно более чем двукратное увеличение государственного финансирования. Кроме того, за счет бюджета обеспечены субсидирование процентной ставки сельхозпредприятиям, реструктуризация долгов, списание пеней и штрафов на общую сумму почти 200 млрд руб.

Таких примеров «пролившегося» над аграрным комплексом России финансового «дождя» еще не было в российской истории.
По логике рыночной экономики можно было бы предположить, что выделяемые инвестиции, хотя бы в близкой пропорции, должны повлиять на эффективность сельского хозяйства и уровень жизни российского населения. В ином случае появляются мысли о других, в том числе криминальных механизмах освоения этих огромных средств.

Подобные сомнения возникают и по той причине, что в официальной статистике и в прессе вряд ли можно найти перечень основных получателей бюджетного «пирога». За редким исключением, это - крупнейшие сельхозпредприятия и регионы, в руководстве которых находятся люди, приближенные к вертикали власти и к финансовым потокам. Кроме элементарных «откатов», руководителям аграрного комплекса выгодно работать с крупными товаропроизводителями, которые имеют возможность страхования убытков, гарантии банковского капитала, счета в зарубежных банках и контролируются соответствующими структурами.

Из этой ситуации следует вывод о том, что невиданный урожай на наших полях является не только следствием глобального потепления климата и заслуг тружеников села, но и результатом гигантских объемов бюджетных вливаний, которые в советское время значительно в меньшем объеме направлялись на поддержание многочисленных малоэффективных коллективных хозяйств, в том числе на развитие сельской инфраструктуры.

В рыночной экономике эти государственные средства в основном пополняют банковские счета аграрных олигархов, которые обязаны в установленные сроки доложить об эффективном освоении выделенных средств. Для таких финансовых потоков введены в оборот новые термины - дотации, субсидии, субвенции, трансферты, беспроцентные кредиты. Кроме того, необходимо успеть получить прибыль, уйти от налогов и вывести капитал за границу.

При существующей кадровой неопределенности на всех уровнях на такие операции должно уйти как можно меньше времени, пока у власти находятся «свои люди». Здесь уже не до сельских клубов и школ. Все это и есть «классика» современного аграрного жанра и основное объяснение его небывалой «эффективности».

В России площадь сельхозугодий составляет 191,286 млн га, из них 117,091 млн га принадлежит крупным собственникам, малым крестьянским хозяйствам досталось 26,069 млн га, и еще 
7,933 млн га отписали на личные участки граждан ${ }^{12}$. Главным поставщиком продовольственных товаров являются сельскохозяйственные предприятия Южного федерального округа, которые произвели в 2016 г. 58\% всего урожая и еще $21 \%$ добавили аграрные регионы Поволжья и Урала, в которых основные площади наиболее плодородных черноземных почв находятся в собственности крупных агрохолдингов ${ }^{13}$.

Знаменитая «кущевская» история - яркое свидетельство событий, которыми сопровождался новый передел земли. Однако если на заре советской власти коллективизацию в интересах всего общества проводили коммунисты, то сегодня приватизацию в интересах узкого круга лиц проводят их потомки - новые реформаторы. При этом оба этих разнонаправленных вектора в равной степени жестоки по отношению к прежним собственникам. Не случайно на тех же степных просторах, знакомых еще из шолоховских произведений, в последние годы появилось множество погостов, где лежат бывшие хозяева колхозных земель.

Теперь крупные агрохолдинги, имеющие доступ к бюджету, - это огромные латифундии на бывших государственных землях. Оборотный капитал позволяет им приобретать современную технику, племенной скот, элитные семена и удобрения, использовать достижения современной науки и новые аграрные технологии, как правило, купленные у зарубежных фирм. По данным С. Кудиярова, на фоне изношенных тракторов и комбайнов большинства сельхозпредприятий почти половина российского парка сельхозмашин состоит из дорогостоящих импортных марок [Кудияров, 2017], которые вряд ли находятся в собственности мелких фермеров.

Общий рост бюджетного финансирования аграрной отрасли, выросший с 262,3 млрд руб. в 2010 г. до 331,7 млрд руб. в 2016 г., как-то «вуалирует» распределение средств на уровне товаропроизводителей ${ }^{14}$. В итоге конечным результатом российских аграрных реформ стало не только достижение рекордных урожаев, но и продолжение традиций недавнего исторического прошлого, когда богатые богатеют, а бедные беднеют.

${ }^{12}$ Сельское хозяйство, охота и охотничье хозяйство, лесоводство в России. 2015 Стат.сб./Росстат. М., 2015. С. 75.

${ }_{13}^{13}$ Основные показатели сельского хозяйства в России в 2016 г. С. 44-65.

${ }^{14}$ Российский стат. ежегодник. 2017. С. 495.
Для сравнения эффективности российского сельского хозяйства можно привести результаты деятельности аграрной отрасли Беларуси, сохранившей систему государственного управления экономикой и полностью обеспеченной собственными продуктами питания. Более того, по официальным данным ФТС, в 2015 г. от наших соседей поступило 77,5\% сливочного масла, $80,4 \%$ сыров и творога. По сравнению с 2000 г. импорт говядины увеличился почти в 15 раз, молока и масла - в четыре раза [Белова, 2017]. Почти во всех крупных российских городах есть фирменные магазины с белорусскими продуктами, соответственно, эффективность аграрной отрасли значительно повышается за счет организации полного цикла - от пашни до реализации конечной продукции. Успехи Беларуси в сельском хозяйстве не могут не восхищать. При этом здесь нет черноземов, гипертрофированного аграрного бюджета и других преференций, а есть эффективная государственная политика в сочетании с прозрачной антикоррупционной борьбой на всех уровнях власти.

Особой темой в аграрном секторе российской экономики является использование химических удобрений. С советских времен наша страна была одним из мировых лидеров в их производстве. Сегодня, после спада 1990-х гг., Россия превзошла советские достижения: объем выпуска отрасли достиг более 20 млн т. Однако если в 1988 г. на внутренние нужды ушло почти 12 млн т удобрений, то в последние годы их потребление едва превышает 2 млн т. При этом в России вносят удобрений в 4-5 раз меньше, чем в Евросоюзе. Еще более плачевная ситуация на российской периферии. И вполне понятно, что рекордных урожаев без удобрений не бывает.

Использование химических удобрений в России возросло только на небольшой части черноземных угодий, производящих рекордные урожаи и принадлежащих крупным финансовым структурам, которые имеют средства на их приобретение. Сокращение поголовья домашнего скота в частном секторе привело к резкому спаду в использовании органических удобрений, поэтому на всей остальной части огромной страны применение удобрений является больше экзотикой, не влияющей на продуктивность земель.

Эффективность мясного и молочного животноводства достигается за счет применения импортных биодобавок, ветеринарных 
препаратов, в том числе лизина, который в основном поставляется из Китая. Однако с 22 декабря 2017 г. Россельхознадзор ввел запрет на поставку в Россию китайского лизина, что может существенно снизить эффективность продукции животноводства.

Кроме того, следует признать, что в большинстве российских регионов невозможно получить достойный урожай без мелиорации земель. Между тем распалась вся система бывшего Министерства мелиорации и водного хозяйства СССР, и сегодня в действующем состоянии находится лишь $27 \%$ мелиоративных систем [Клюева, 2017]. К этому следует добавить, что с развалом плановой экономики разрушилась и вся агрохимическая служба, которая оценивала качественное состояние почв. На селе остро не хватает специалистов-аграриев. На зарастающих кустарником заброшенных землях резко увеличилось количество лесных и торфяных пожаров.

\section{Локомотив российской экономики в регионах}

В Республике Бурятия, расположенной в зоне рискованного сельского хозяйства, из года в год сокращается площадь обрабатываемых земель. По итогам 2017 г., на фоне российского изобилия в республике погибла треть урожая, а фермеры оформили документы на 309 млн руб. в качестве компенсации потерь. При себестоимости 1 кг продовольственного зерна 5,5 руб. на эту сумму можно купить более 50 тыс. т зерна без всяких затрат.

Следует отметить, что ориентация существующей аграрной политики на крупные хозяйства не решает проблемы занятости сельского населения. Более того, сокращение численности занятых на селе учитывается статистикой как положительный фактор повышения производительности труда. Как правило, на таких сельскохозяйственных предприятиях производство носит промышленный характер, используется небольшой штат квалифицированных высокооплачиваемых, в том числе зарубежных кадров. В отличие от руководителей хозяйств советского времени, новые хозяева земли могут и не посещать свою собственность, соответственно, у них нет необходимости вкладываться в развитие социальной инфраструктуры для села.

Мелкие фермеры не в состоянии конкурировать с таким производством ни по объемам продукции, ни по ценообразованию, поскольку сетевым магазинам необходимы крупные поставки с гарантированными объемами и качеством. Кроме того, новые хозяева земли чаще всего юридически регистрируются в крупных городах по месту расположения головной фирмы, что исключает поступление налогов в местный бюджет. Поэтому в условиях массовой сельской безработицы такие предприятия вызывают резкое неприятие сельского населения, иногда переходящее, по канонам классовой борьбы, в агрессивные действия.

В погоне за рекордными объемами производства руководство страны оставило без внимания другую очень важную функцию аграрной экономики - сохранение сельского населения. Здесь уже не приходится говорить о перспективном развитии наших сел и деревень, во все времена сохранявших основу российской государственности [Тулохонов, 2014].

Только за период между переписями 2002 г. и 2010 г. с карты России исчезло 8,5 тыс. сел и деревень и еще в 19,4 тыс. существующих почтовых адресов жизнь пока теплится, но их жители уже обходятся без света и транспортного сообщения ${ }^{15}$. В результате урбанизации российское село за полвека потеряло почти 20 млн человек, и следующая перепись населения только добавит новые миллионы сельчан, покинувших малую родину.

После выхода постановления о реформе Российской академии наук упразднена Академия сельскохозяйственных наук с ее многочисленными институтами, агрохимическими, ветеринарными и семенными станциями. Теперь сотрудники вместо решения отраслевых задач сельского хозяйства вынуждены писать публикации в рейтинговые журналы, по которым будет оцениваться уровень их работы. В условиях рыночной экономики сельскохозяйственная наука не может существовать без государственной поддержки.

Крупный российский аграрный бизнес более всего стремится к быстрой окупаемости вложенных средств. Он мало заинтересован в создании новых российских районированных сортов сельскохозяйственных растений и высокопродуктивных пород животных, требующих длительной научной селекции. Значительно проще купить то же самое за границей. Хотя известно, что зарубежные аналоги мало приспособлены для суровых российских

${ }^{15}$ Об итогах Всероссийской переписи населения 2010 года Федеральная служба гос. статистики [Эл. ресурс]. URL: www.gks.ru/free_doc/new_site/population/demo/ per-itog/rg-14-12.doc. (дата обращения: 08.02.2018). 
природных условий, а культурные растения требуют постоянного восстановления репродуктивных свойств.

Отсюда логично следует другой вывод: сельское хозяйство, ориентированное только на крупнотоннажное производство на основе использования зарубежной техники и технологий, импортных поставок элитных семян и племенных животных, не может гарантировать решение проблемы продовольственной безопасности страны.

На этом фоне в практику многих хозяйств Бурятии и других российских регионов вошли зарубежные поездки руководителей по изучению передового опыта, итогом которых становится приобретение по целевым программам и кредитам импортных высокопродуктивных молочных пород скота, дающих на их родине рекордные надои. Как правило, такие эксперименты в наших реалиях не приносят ожидаемых результатов по той простой причине, что новые фермеры не представляют сложность современного аграрного процесса и не могут обеспечить стадо необходимыми кормами, технологией содержания и племенной работой.

К числу важнейших задач сельскохозяйственной науки следует отнести проведение современного агроклиматического районирования всех обрабатываемых земель с учетом изменившихся за годы реформ природных условий, состояния почв и потребностей рынка. На огромной территории нашей страны невозможен единый механизм реформирования и реализации национальных проектов в разных областях экономики [Тулохонов, 2006].

Регионы с различным аграрным потенциалом должны не конкурировать между собой в производстве одних и тех же товаров, а дополнять друг друга, удовлетворяя потребности всего российского населения в тех или иных продуктах питания. Определяющими факторами становятся стоимость товара и его доступность, что предполагает восстановление функции Госплана.

Между тем в последние годы основная часть российского сельского населения существует в режиме «самообеспечения». При этом оно уже не надеется на государственную поддержку, которая обложена неподъемными для села бюрократическими процедурами. В наши дни фермерство более всего нуждается от государства в восстановлении системы потребкооперации, которая могла бы обеспечить закупку продукции и ее реализацию, а вместо мелких «подачек» и кредитов, приходящих уже после сбора урожая, обеспечила бы достойную ценовую политику закупки продуктов органического сельского хозяйства.

В этих условиях на российской периферии возрождаются фермерские хозяйства на родовых землях. В Республике Бурятия подобным образом вновь осваиваются брошенные земли в удаленных от столицы районах, где преобладает коренное население, которое еще сохраняет связи с малой родиной. При этом оно большей частью ориентировано на традиционное мясное животноводство на основе аборигенных пород скота, максимально приспособленного к использованию подножного корма и суровым климатическим условиям Великой степи. Такие мелкотоварные семейные предприятия чаще всего не входят в систему государственной статистики и потому не портят его показатели.

Из всей этой ситуации следует главный вывод о том, что локомотив аграрной экономики должен обеспечивать не только рекордные достижения в производстве отдельных видов продовольствия, а более всего стремиться к системному решению основных проблем всей отрасли, в первую очередь повышению уровня жизни российского населения. Отдельные, даже самые радужные показатели статистики, не отражают состояние всего сельского хозяйства, включая рост цен на продовольствие, недостаток удобрений и в конечном итоге - прогрессирующее ухудшение качества земельных угодий, нехватку квалифицированных кадров и безработицу на селе, разрушение системы мелиорации и другие проблемы. А массовое сокращение сельского населения страны и есть основной показатель состояния российского села и всей аграрной отрасли.

\section{Куда двигаться локомотиву российской экономики}

Приоритетной задачей сельского хозяйства становится не просто увеличение объемов продукции и экспорт продовольственного сырья, а прежде всего его переработка на внутреннем рынке с целью получения продовольственных товаров с более высокой добавленной стоимостью. Кроме того, следует ограничить чрезмерную эксплуатацию южных российских черноземов, продуктивность которых мы обязаны сохранить для будущих 
поколений. Повышение эффективности аграрного сектора экономики предполагает введение механизма рентных отношений, который наряду с более объективным перераспределением бюджетных средств должен стимулировать сельскохозяйственное производство в регионах с менее плодородными землями и худшими природно-климатическими условиями.

Следует изменить представление о продовольственной безопасности страны, которое традиционно понимается как простое достижение абстрактных показателей производства и потребления собственных продуктов питания на душу населения. Такая задача должна решаться на базе использования новых технических средств, современных наукоемких технологий, отечественных высокопродуктивных семян и пород животных, созданных в российских условиях и не зависящих от импортных поставок.

Главным условием стабильности государственного устройства России в новых геополитических и экономических реалиях остается задача сохранения потенциала сельского населения. Российское село по-прежнему остается ключевым источником пополнения продовольственной корзины для основной части населения, а кроме того, относится к главным социальным скрепам нашего общества, сохраняющим территориальную целостность и устойчивость государства.

\section{Литература}

Аганбегян А.Г. Сельское хозяйство-локомотив социально-экономического роста России // ЭКО. 2017. № 5. С. 5-22.

Белова T.Н. Искусство аграрной политики: протекционизм или свободная торговля? // ЭКО. 2017. № 5. С. 61-75.

Жога Г. Южный цвет // Российский экспортер. 2017. № 3 (5). С. 106-111. Клюев Н.Н. Аграрное природопользование в российских регионах: эколого-ресурсный «диссонанс» // Известия РГО. 2017. Т. 149. Вып. 3. С. 4-13.

Кудияров С. Возможности роста. Экспорт продукции энергетического машиностроения в 2016 году // Российский экспортер. 2017 № 3 (5). C. 78-83.http://webcache.googleusercontent.com/search?q=cache: M1oROXY5C7IJ: www.gks.ru/free_doc/new_site/population/demo/per-itog/rg-14 12. $\mathrm{doc}+\& \mathrm{~cd}=10 \& \mathrm{hl}=\mathrm{ru} \& \mathrm{ct}=\mathrm{clnk} \& \mathrm{gl}=\mathrm{ru}$

Скрынник Е.Б. В борьбе за продовольственный суверенитет // Эксперт. 2017. № 1-2. С. $38-39$.

Столыпин П.А., Кривочеин А.В. Поездка в Сибирь и Поволжье. Записка. Спб. 1911.

Тулохонов А.К. О подходах к реализации национальных проектов // Экономист. 2006. № 5. С. 10-12.
Тулохонов А. К. Политическая география Северной Азии в условиях глобализации или как обустроить российскую периферию. Улан-Удэ. 2014

Статья получена 14.02.2018.

\section{Summary}

Tulokhonov A. K., Baikal Institute of Nature Management, SB RAS, Ulan-Ude Again about "the Struggle" with the Harvest or Where the Engine of the Russian Economy is Going

The article defines the main aspects of the development of Russian agriculture. The analysis of the effectiveness of state support for agriculture was carried out. It is concluded that in a market economy, agricultural science can not exist without state support. It is emphasized that the main condition for the stability of the state structure of Russia in the new geopolitical and economic circumstances remains the task of preserving the potential of the rural population.

Agriculture economics; food security; agricultural science; state support for agriculture

\section{References}

Aganbegjan A.G. (2017) Sel'skoe hozjajstvo - lokomotiv social'nojekonomicheskogo rosta Rossii. JeKO [ECO]. № 5. Pp. 5-22. (In Russ.)

Belova T.N. (2017) Iskusstvo agrarnoj politiki: protekcionizm ili svobodnaja torgovlja? JeKO [ECO]. № 5. Pp. 61-75.(In Russ.)

Zhoga G.(2017) Juzhnyj cvet. Rossijskij jeksporter [Russian Exporter]. № 3 (5). Pp. 106-111. (In Russ.)

Kljuev N. N. (2017) Agrarnoe prirodopol'zovanie v rossijskih regionah: jekologoresursnyj «dissonans». Izvestija RGO. T. 149. Vyp. 3. Pp. 4-13. (In Russ.)

Kudijarov S. (2017) Vozmozhnosti rosta. Jeksport produkcii jenergeticheskogo mashinostroenija v 2016 godu. Rossijskij jeksporter [Russian Exporter]. № 3 (5). Pp. 78-83. (In Russ.)

Skrynnik E. B. (2017) V bor'be za prodovol'stvennyj suverenitet. Jekspert [Expert]. № 1-2. Pp. 38-39.(In Russ.) spb.

Stolypin P.A., Krivoshein A.V. (1911) Poezdka v Sibir' i Povolzh'e. Zapiska.

Tulohonov A.K. (2006) O podhodah k realizacii nacional'nyh proektov Jekonomist [Economist]. № 5. Pp.10-12. (In Russ.)

Tulohonov A.K.(2014). Politicheskaja geografija Severnoj Azii v uslovijah globalizacii ili kak obustroit' rossijskuju periferiju. Ulan-Udje. 